\title{
Efficacy and Safety of IDegLira in Participants with Type 2 Diabetes in India Uncontrolled on Oral Antidiabetic Drugs and Basal Insulin: Data from the DUAL Clinical Trial Program
}

\author{
Kamlesh Khunti • Viswanathan Mohan · Sunil M. Jain • \\ Trine Welløv Boesgaard · Kamilla Begtrup · Bipin Sethi
}

Received: February 7, 2017 / Published online: March 22, 2017

(C) The Author(s) 2017. This article is an open access publication

\section{ABSTRACT}

Introduction: The efficacy and safety of insulin degludec/liraglutide (IDegLira) has been evaluated in the Dual Action of Liraglutide and Insulin Degludec in Type 2 Diabetes (DUAL) phase 3 clinical trial program. In this post hoc analysis, we compared the efficacy and safety of IDegLira in the Indian subpopulation with the

Enhanced content To view enhanced content for this article go to: http://www.medengine.com/Redeem/ 39F7F0600921A8B9.

K. Khunti $(\bowtie)$

Diabetes Research Centre, Leicester Diabetes Centre, University of Leicester, Leicester, UK

e-mail: kk22@leicester.ac.uk

\section{Mohan}

Department of Diabetology, Madras Diabetes Research Foundation and Dr. Mohan's Diabetes Specialities Centre, Chennai, India

\section{S. M. Jain}

Endocrinology, TOTALL Diabetes Hormone

Institute, Indore, Madhya Pradesh, India

T. W. Boesgaard

Medical and Science, Novo Nordisk A/S, Søborg,

Denmark

K. Begtrup

Biostatistics, Novo Nordisk A/S, Søborg, Denmark

B. Sethi

Endocrinology Unit, CARE Hospitals, Hyderabad, India results from the global trial population of DUAL trials. The analysis includes participants uncontrolled on oral antidiabetic drugs (OADs) in DUAL I and DUAL IV and participants uncontrolled on basal insulin and OADs in DUAL II.

Methods: Three phase 3 trials were included in the analysis: DUAL I extension (IDegLira vs. insulin degludec or liraglutide $1.8 \mathrm{mg}$ in participants uncontrolled on metformin \pm pioglitazone; 52 weeks; $n=1663$ ), DUAL IV (IDegLira vs. placebo as an add-on to a regimen of sulfonylurea \pm metformin; 26 weeks; $n=435$ ) and DUAL II (IDegLira vs. insulin degludec in participants uncontrolled on basal insulin + OADs; 26 weeks; $n=398$ ). There were 251,64 and 64 participants, respectively, at the Indian sites.

Results: In the Indian subpopulations, the reductions in glycated hemoglobin $\left(\mathrm{HbA}_{1 \mathrm{c}}\right)$ with IDegLira were substantial [DUAL I: $1.96 \%$ $(-21 \mathrm{mmol} / \mathrm{mol}) ; \quad$ DUAL $\quad \mathrm{IV}: \quad-1.40 \% \quad(-15$ $\mathrm{mmol} / \mathrm{mol}) ;$ DUAL II: $-2.20 \% \quad(-24 \mathrm{mmol} /$ mol)] and significantly greater than those in the comparators in each trial. IDegLira was generally weight-neutral after the administration of OADs $(-0.3$ and $+0.6 \mathrm{~kg}$ in DUAL I and DUAL IV) and resulted in weight loss after the administration of basal insulin $(-2.1 \mathrm{~kg}$ in DUAL II). Hypoglycemia rates were 1.98, 1.08 and 0.37 events/patient-years of exposure (PYE) for IDegLira, insulin degludec and liraglutide in DUAL I, 4.06 and 0.36 events/PYE for IDegLira and placebo in DUAL IV and 1.16 and 0.83 
events/PYE with IDegLira and insulin degludec in DUAL II.

Conclusions: Results from the Indian subpopulations reflect those of the global study populations, supporting IDegLira as an effective and safe treatment option for people with type 2 diabetes inadequately controlled on OADs or basal insulin + OADs in the South Asian population.

Trial Registration: ClinicalTrials.gov identifier, NCT01336023 (DUAL I), NCT01392573 (DUAL II), NCT01618162 (DUAL IV).

Funding: Novo Nordisk A/S, Bagsvaerd, Denmark.

Keywords: IDegLira; Indian population; Type 2 Diabetes

\section{INTRODUCTION}

India has the second highest number of people with diabetes worldwide, with approximately $8.6 \%$ of the population reported to have this disease [1]. Glycemic control is poor in Indian diabetic patients, with a mean glycated hemoglobin $\left(\mathrm{HbA}_{1 \mathrm{c}}\right) \quad$ of $\quad 8.9 \pm 2.1 \%$ $(74 \pm 23 \mathrm{mmol} / \mathrm{mol})$ and only $19.7 \%$ of the Indian diabetic population achieving the American Diabetes Association/European Association for the Study of Diabetes $\mathrm{HbA}_{1 \mathrm{c}}$ target of $<7 \%(<53 \mathrm{mmol} / \mathrm{mol})[2,3]$. In addition to the increased prevalence of diabetes, higher rates of diabetes-related complications and mortality are also observed in South Asian people [4]. The factors contributing to this situation are multifactorial and include a genetic predisposition to diabetes, increased visceral adiposity and insulin resistance in this population, which are compounded by lifestyle factors [5]. Despite these numbers, South Asian participants in trials of glucose-lowering therapies are under-represented [6]; hence, it is important to report trial data from diverse populations.

IDegLira is a novel, once-daily, titratable, fixed-ratio combination of insulin degludec (IDeg) and the glucagon-like peptide-1 receptor agonist (GLP-1RA) liraglutide (Lira) that has been developed for the treatment of people with type 2 diabetes [7-9]. Importantly, GLP-1RAs act in a glucose-dependent manner and are also commonly associated with a low risk of hypoglycemia and weight loss [10]. The efficacy and safety of IDegLira and the benefits of its complementary mode of action have been examined in the large global DUAL clinical trial program [7-9, 11]. Here we describe a post hoc analysis of the efficacy and safety of IDegLira in participants from Indian trial sites included in the DUAL program. Our hypothesis was that the safety and efficacy of IDegLira in the Indian subpopulation would be similar to that demonstrated for the global population.

\section{METHODS}

This post hoc analysis used data from the IDegLira (Novo Nordisk, Bagsværd, Denmark) phase 3 trials which included participants with type 2 diabetes from Indian trial sites, namely, the DUAL I extension (52 weeks of data), DUAL IV and DUAL II trials, which included Indian sites $[8,9,11]$.

\section{Study Designs}

The study designs of DUAL I extension, DUAL II and DUAL IV have been described previously $[8,9,11]$ and include participants uncontrolled on oral antidiabetic drugs (OADs; DUAL I extension and DUAL IV) and participants uncontrolled on basal insulin + OADs (DUAL II). The aim of DUAL I extension was to investigate the efficacy and safety of IDegLira versus its individual components IDeg or Lira alone in participants inadequately controlled by metformin \pm pioglitazone over 52 weeks [8]. In DUAL IV IDegLira was compared with placebo, both added on to a therapeutic regimen of sulphonylurea \pm metformin [9], and in DUAL II, IDegLira was compared to IDeg (maximum dose of $50 \mathrm{U}$ ) in participants inadequately controlled on 20-40 U of basal insulin + one to two OADs [11]. Owing to differences in trial design, individual trial data were analyzed separately, rather than pooling the IDegLira data. 


\section{Endpoints and Statistical Analyses}

The primary endpoint in each study was change from baseline in $\mathrm{HbA}_{1 \mathrm{c}}$. Secondary efficacy endpoints included participants achieving a $\mathrm{HbA}_{1 \mathrm{c}}$ of $<7 \%(<53 \mathrm{mmol} / \mathrm{mol})$, change in body weight, insulin dose and laboratory-measured fasting plasma glucose (FPG). Safety endpoints included adverse events (AEs) and confirmed hypoglycemia [severe (unable to self-treat) and/ or plasma glucose level of $<3.11 \mathrm{mmol} / \mathrm{L}]$. Change from baseline in $\mathrm{HbA}_{1 \mathrm{c}}$, FPG and body weight were analyzed using an analysis of covariance (ANCOVA) model with treatment and pre-trial medication as fixed factors, and baseline $\mathrm{HbA}_{1 \mathrm{c}}$ stratum (DUAL I only), substudy (DUAL I only) and baseline value as covariates-all performed on the full analysis set using last observation carried forward (LOCF) method to impute missing values. Attainment of a $\mathrm{HbA}_{1 \mathrm{c}}$ level of $<7 \%$ was analyzed using a logistic regression model (with LOCF), with the same explanatory variables as used for the primary endpoint. The results of the analyses were also summarized descriptively for other endpoints (insulin dose, rates of hypoglycemia and other safety endpoints).

As a post hoc analysis, the original individual trials were not powered to perform statistical analyses in the Indian subpopulations. The study reported here is based on a post hoc analysis of previously conducted studies and does not involve any new studies of human or animal subjects performed by any of the authors.

\section{RESULTS}

The Indian subpopulations comprised 15, 16 and $15 \%$ of the global trial populations of the DUAL I extension, DUAL II and DUAL IV trials, corresponding to 251, 64 and 64 participants, respectively. Baseline characteristics of the global trial populations and Indian subpopulations are shown in Table 1. Overall, the baseline characteristics of the Indian subpopulations were largely comparable to those of the global trial populations, although the Indian participants had lower FPG and body mass index (BMI).

\section{Glucose Control}

The change in $\mathrm{HbA}_{1 \mathrm{c}}$ from baseline and end-of-trial $\mathrm{HbA}_{1 \mathrm{c}}$ in the global study populations and the Indian subpopulations from the three studies are shown by patient population in Fig. 1. Considering patients previously uncontrolled on $\mathrm{OAD}(\mathrm{s})$, in the Indian subpopulation of DUAL I extension, IDegLira resulted in a statistically significantly greater $\mathrm{HbA}_{1 \mathrm{c}}$ reduction versus IDeg [estimated treatment difference (ETD) $-0.91 \%$; 95\% confidence interval $(\mathrm{CI})-1.21$ to $-0.61(-10 \mathrm{mmol} / \mathrm{mol}$; 95\% CI -13 to -7$) ; p<0.0001]$ and versus Lira [ETD $-0.77 \% ; \quad 95 \%$ CI -1.08 to -0.46 $(-8 \mathrm{mmol} / \mathrm{mol} ; 95 \% \mathrm{CI}-12$ to -5$) ; p<0.0001]$. In DUAL IV, a significantly greater reduction was observed with IDegLira versus placebo [ETD: $-0.78 \% ; \quad 95 \%$ CI -1.25 to -0.31 ( $-9 \mathrm{mmol} / \mathrm{mol} ; 95 \% \mathrm{CI}-14$ to -3 ); $p=0.002$ ] in the Indian subpopulation. In patients previously uncontrolled on basal insulin (DUAL II), IDegLira also resulted in a greater $\mathrm{HbA}_{1 \mathrm{c}}$ reduction versus IDeg [maximum dose $50 \mathrm{U}$; ETD $-1.32 \%$; $95 \%$ CI -1.80 to -0.85 $(-14 \mathrm{mmol} / \mathrm{mol} ; \quad 95 \% \quad \mathrm{CI} \quad-20$ to -9$)$; $p<0.0001]$ in the Indian subpopulation.

The proportion of participants in the global study populations and the Indian subpopulations achieving $\mathrm{HbA}_{1 \mathrm{c}}<7 \%(<53 \mathrm{mmol} / \mathrm{mol})$ are shown in Fig. 2. In the Indian subpopulation of the DUAL I extension trial, participants were significantly more likely to achieve an $\mathrm{HbA}_{1 \mathrm{c}}$ of $<7 \%(<53 \mathrm{mmol} / \mathrm{mol})$ with IDegLira than with IDeg [84.0 vs. $43.1 \%$; odds ratio (OR) $6.77 ; 95 \%$ CI 3.35-13.65; $p<0.0001]$ or with Lira (84.0 vs. 47.5\%; OR 5.84; 95\% CI 2.86-11.90; $p<0.0001)$. Participants were also more likely to achieve an $\mathrm{HbA}_{1 \mathrm{c}}$ of $<7 \%(<53 \mathrm{mmol} / \mathrm{mol})$ with IDegLira than with placebo in the DUAL IV trial (69.6 vs. $16.7 \%$; OR $11.47 ; 95 \%$ CI 2.79-47.17; $p<0.001)$. In DUAL II, participants were also more likely to achieve an $\mathrm{HbA}_{1 \mathrm{c}}$ of $<7 \%$ (53 mmol/mol) with IDegLira versus IDeg (65.6 vs. $21.9 \%$; OR 7.36 ; $95 \%$ CI $2.31-23.50$; $p<0.0007)$. 


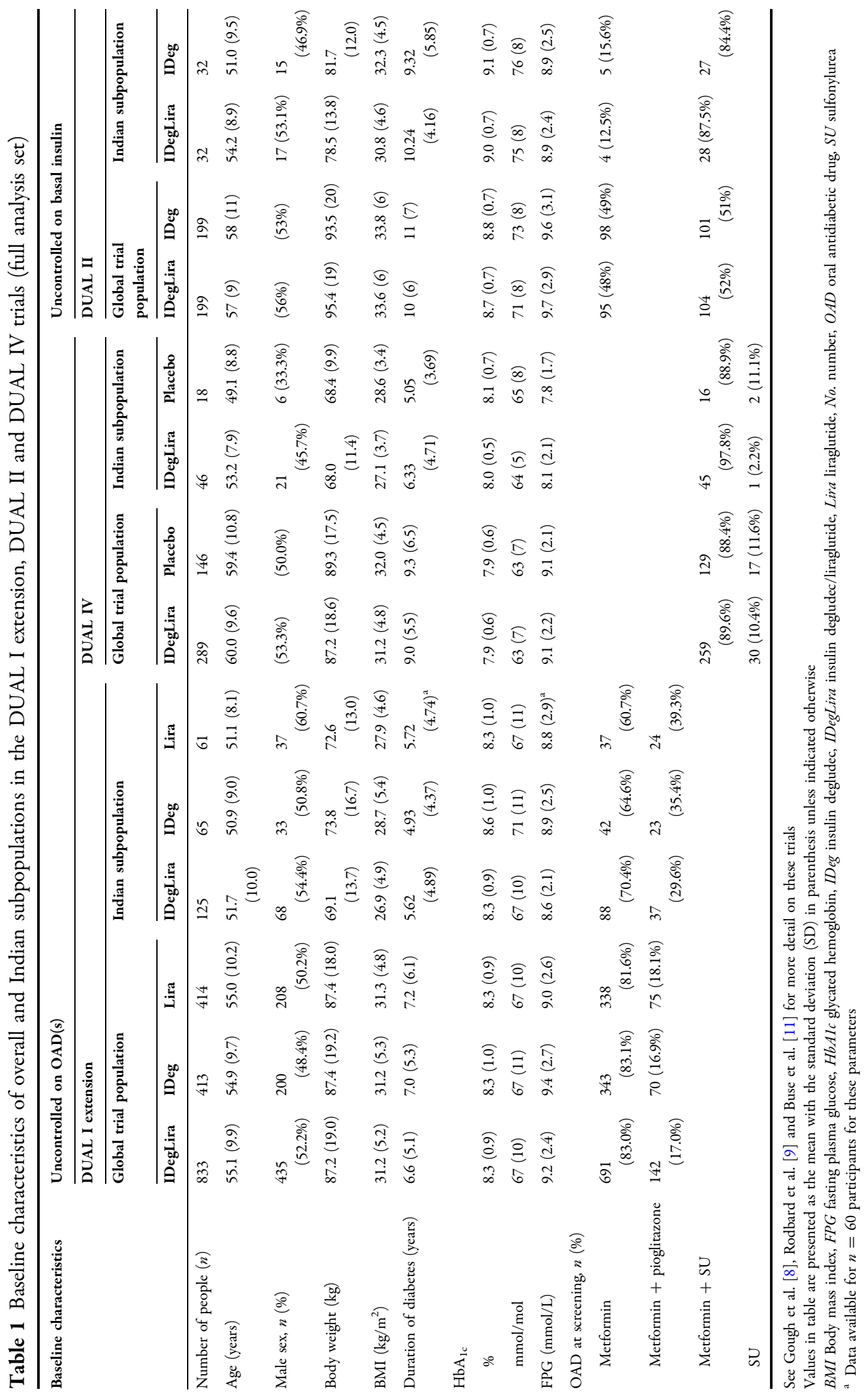




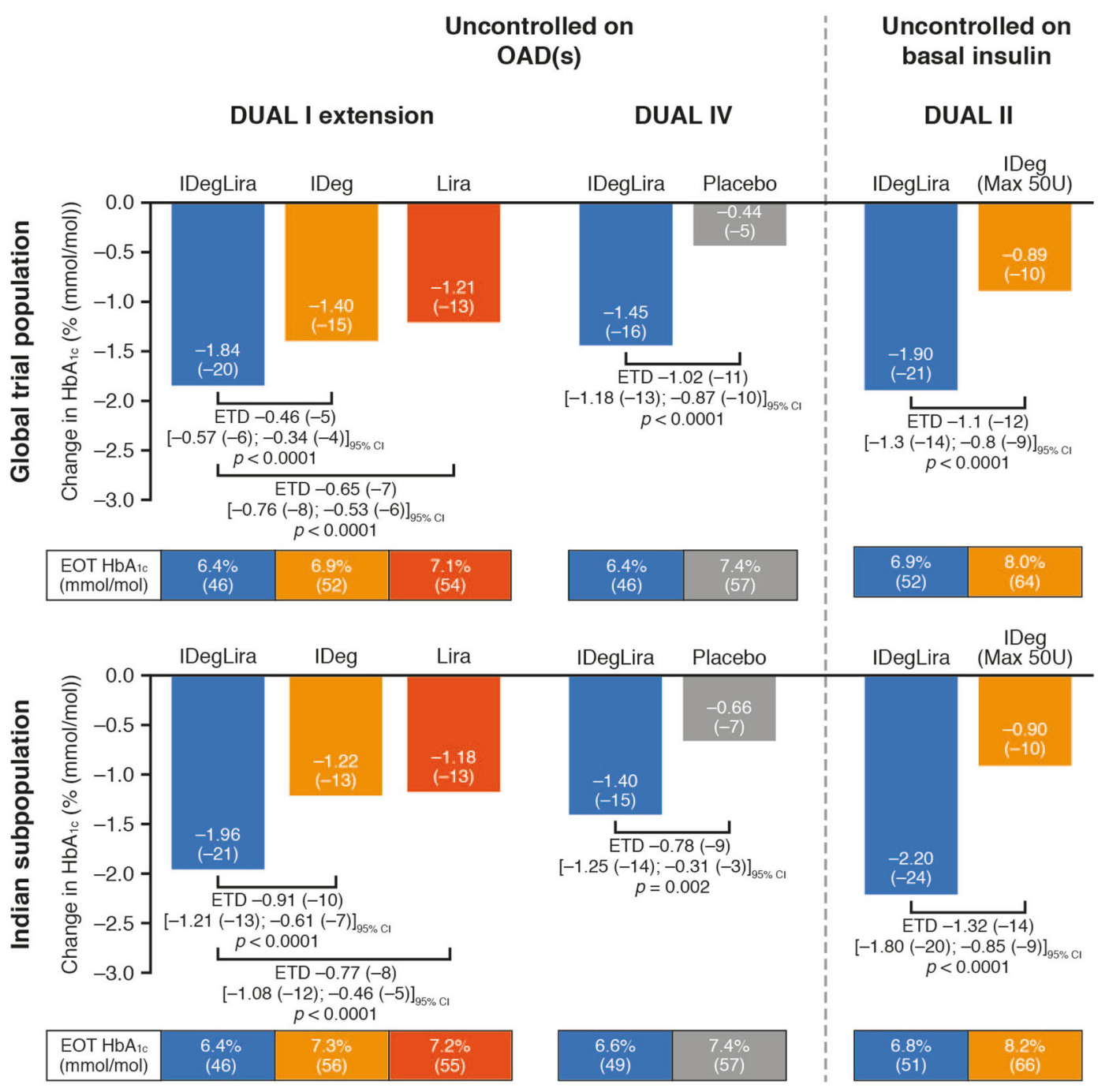

Fig. 1 Mean change in glycated hemoglobin $\left(\mathrm{HbA}_{1 \mathrm{c}}\right)$ and end-of-trial $\mathrm{HbA}_{\mathrm{lc}}$ in the global study population and the Indian subpopulations of the DUAL I extension, DUAL IV and DUAL II trials (maximum $50 \mathrm{U}$ ) $[8,9,11,12]$. Mean observed values are based on full analysis set and data inputted using the last observation carried forward

In the DUAL I extension trial, IDegLira resulted in a greater FPG reduction versus Lira (ETD $-29.80 \mathrm{mg} / \mathrm{dL} ; 95 \% \mathrm{CI}-39.62$ to -19.98 ; $p<0.0001)$; differences versus IDeg were not statistically significant [TD $-7.04 \mathrm{mg} / \mathrm{dL} ; 95 \%$ CI -16.57 to $2.50 ; p=$ not significant (ns)]. Differences versus placebo in the DUAL IV trial were also not statistically significant (ETD $-18.65 \mathrm{mg} / \mathrm{dL} ; 95 \% \mathrm{CI}-38.80$ to $1.50 ; p=\mathrm{ns}$ ). IDegLira resulted in a greater FPG reduction versus IDeg (maximum dose $50 \mathrm{U}$ ) in DUAL II

(LOCF) method. Treatment difference is estimated from an analysis of covariance (ANCOVA) analysis. CI Confidence interval EOT end of trial, ETD estimated treatment difference, IDeg insulin degludec, IDegLira insulin degludec/liraglutide, Lira liraglutide, $O A D$ oral antidiabetic drug

(ETD $-34.26 \mathrm{mg} / \mathrm{dL} ; 95 \% \mathrm{CI}-53.28$ to -15.24 ; $p=0.0006)$.

\section{Body Weight}

In the Indian subpopulation of the DUAL I extension trial, IDegLira was weight neutral $(-0.3 \mathrm{~kg})$, whereas body weight increased with IDeg $(1.8 \mathrm{~kg}$; ETD $-1.61 \mathrm{~kg}$; $95 \%$ CI -2.45 to $-0.78 ; p=0.0002)$ and decreased with Lira 


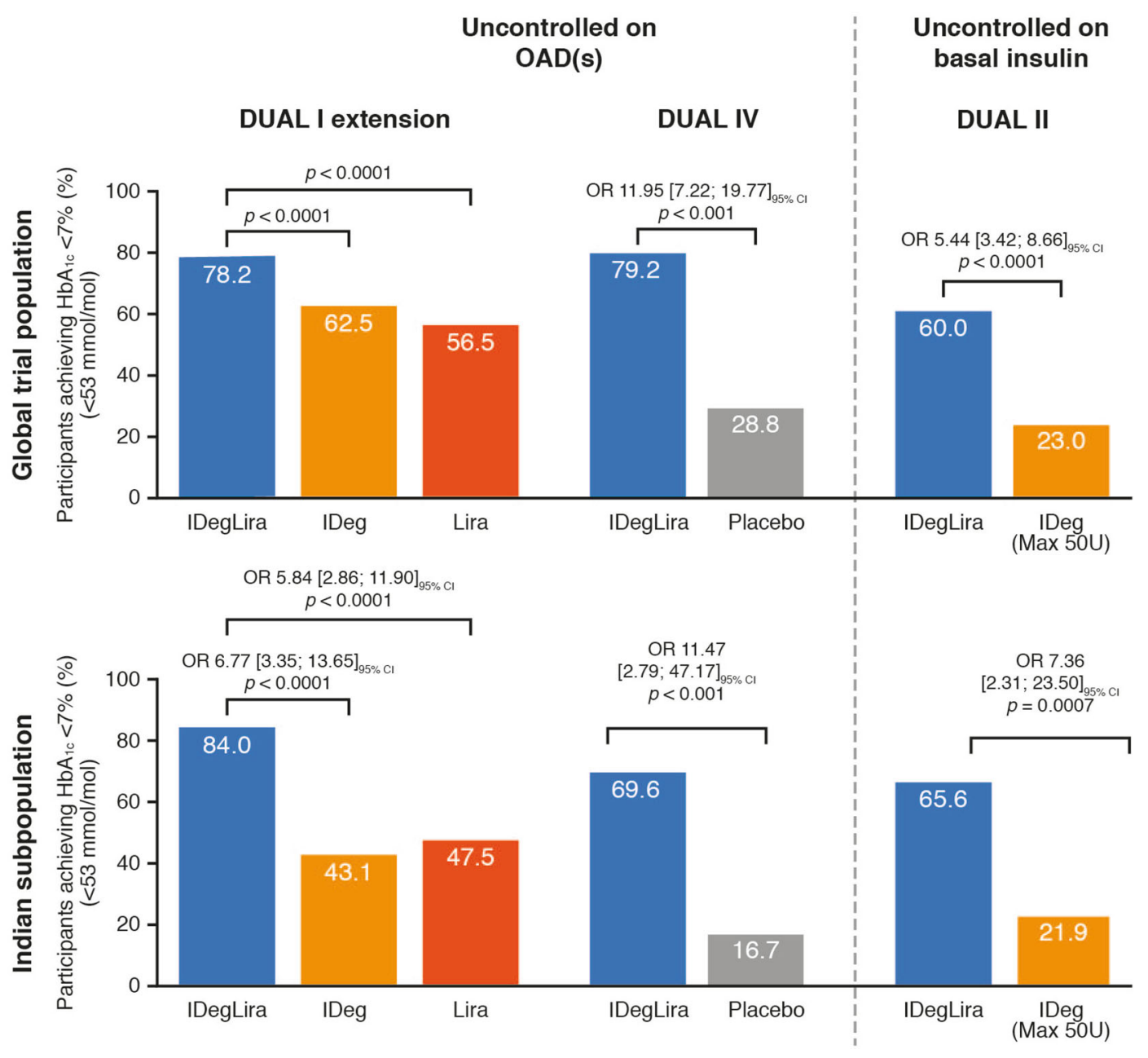

Fig. 2 Percentages of participants achieving the $\mathrm{HbA}_{1 \mathrm{c}}$ target of $<7 \%$ in the global study population and the Indian subpopulations of the DUAL I extension, DUAL IV and DUAL II trials (maximum $50 \mathrm{U}$ ) [8, 9, 11, 12].

$(-2.3 \mathrm{~kg} ; \quad$ ETD $1.72 \mathrm{~kg} ; \quad 95 \%$ CI $0.87-2.58$; $p<0.0001$ ) (Fig. 3). In DUAL IV, the mean weight change was $0.6 \mathrm{~kg}$ with IDegLira and $-0.9 \mathrm{~kg}$ with placebo (ETD $1.37 \mathrm{~kg} ; 95 \% \mathrm{CI}$ $0.31-2.43 ; p=0.0124)$. IDegLira resulted in a greater weight loss versus IDeg (ETD $-1.91 \mathrm{~kg}$; $95 \% \mathrm{CI}-3.39$ to $-0.43 ; p=0.01223$ ) in DUAL II. Across the studies, baseline body weights were lower in the Indian subpopulations.

\section{Insulin Dose}

End-of-trial insulin dose was $35 \mathrm{U}$ with IDegLira and $59 \mathrm{U}$ with IDeg in the DUAL I extension
Mean observed values are based on the full analysis set and LOCF inputted data. The odds ratio $(O R)$ is estimated from a logistic regression analysis

trial, $25 \mathrm{U}$ with IDegLira in the DUAL IV trial and 42 and $46 \mathrm{U}$ with IDegLira and IDeg in the DUAL II trial.

\section{Safety Endpoints}

Adverse events for the global populations and Indian subpopulations are summarized in Table 2. Rates of gastrointestinal AEs (combined diarrhea, nausea and vomiting) were 25.3 events per 100 patient-years of exposure (PYE) in the IDegLira group, 8.5 per 100 PYE in the IDeg group and 75.3 per 100 PYE in the Liratreated group in the DUAL I extension trial, and 


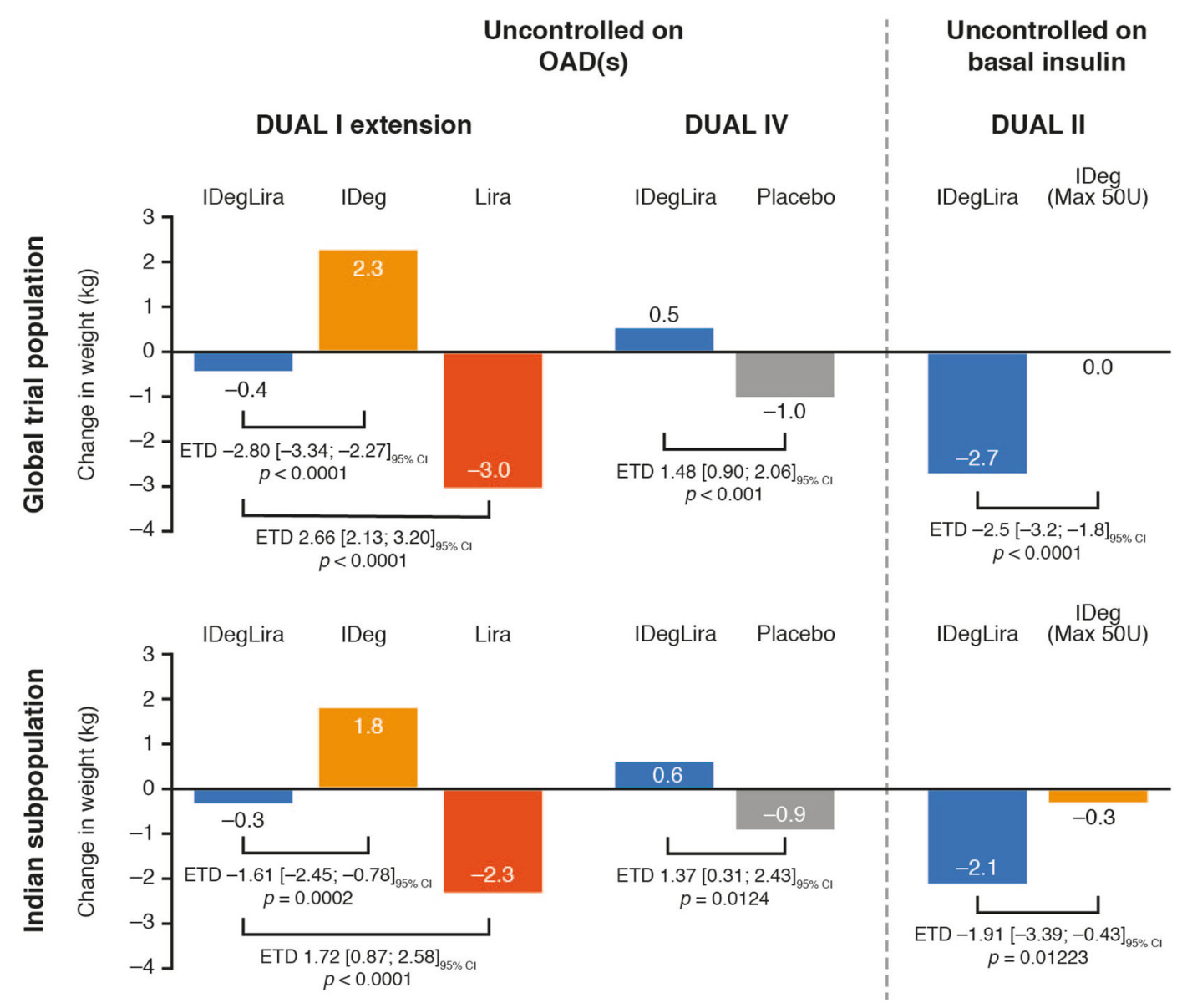

Fig. 3 Mean change in body weight in the global study population and Indian subpopulations of the DUAL I extension, DUAL II and DUAL IV trials $[8,9,11]$. Maximum dose of IDeg was $50 \mathrm{U}$ in DUAL II. Mean

9.4 (IDegLira) and 36.2 (placebo) events/100 PYE in DUAL IV. In DUAL II, the rates were 82.1 (IDegLira) and 20.7 (IDeg) events/100 PYE.

There were no severe hypoglycemic episodes in the Indian subpopulations of the three trials. Confirmed hypoglycemia rates were $1.98,1.08$ and 0.37 events/PYE in the IDegLira, IDeg and Lira groups, respectively, in the DUAL I extension trial (compared with $1.77,2.79$ and 0.19 events/PYE in the global trial population) and 4.06 and 0.36 events/ PYE with IDegLira and placebo, respectively, in DUAL IV (compared with 3.52 and 1.35 events/PYE in the global trial population). In DUAL II, confirmed hypoglycemia rates were 1.16 and 0.83 events/PYE with IDegLira and observed values are based on full analysis set and LOCF inputted data. Treatment difference is estimated from an ANCOVA analysis

IDeg, respectively (compared with 1.53 and 2.63 events/PYE in the global trial population).

\section{DISCUSSION}

In the Indian subpopulations, IDegLira resulted in substantial $\mathrm{HbA}_{1 \mathrm{c}}$ reductions that were significantly greater than those achieved by all comparators. Mean end-of-trial $\mathrm{HbA}_{1 \mathrm{c}}$ with IDegLira was $<7 \%(<53 \mathrm{mmol} / \mathrm{mol})$ in all trials and more participants achieved a $\mathrm{HbA}_{1 \mathrm{c}}$ target of $<7 \%$ ( $<53 \mathrm{mmol} / \mathrm{mol}$ ) versus all comparators, consistent with the global trial populations $[8,9,11]$. 
Table 2 Adverse events reported in the DUAL I extension, DUAL II and DUAL IV trials (full analysis set)

\begin{tabular}{|c|c|c|c|c|c|c|c|}
\hline \multirow[t]{3}{*}{ Adverse events } & \multicolumn{5}{|c|}{ Uncontrolled on $\mathrm{OAD}(\mathrm{s})$} & \multirow{2}{*}{\multicolumn{2}{|c|}{$\begin{array}{l}\text { Uncontrolled on basal } \\
\text { insulin }\end{array}$}} \\
\hline & \multicolumn{3}{|c|}{ DUAL I extension } & \multicolumn{2}{|l|}{ DUAL IV } & & \\
\hline & IDegLira & IDeg & Lira & IDegLira & Placebo & IDegLira & IDeg \\
\hline \multicolumn{8}{|l|}{ Global trial population } \\
\hline Number of exposed participants & 825 & 412 & 412 & 288 & 146 & 199 & 199 \\
\hline Percentage of participants with AEs & 71.2 & 70.6 & 77.2 & $\mathrm{~N} / \mathrm{A}^{\mathrm{a}}$ & $\mathrm{N} / \mathrm{A}^{\mathrm{a}}$ & 57.8 & 61.3 \\
\hline $\mathrm{AE}$ rate per $100 \mathrm{PYE}$ & 407.9 & 383.3 & 507.3 & 401.4 & 367.0 & 398.1 & 355.5 \\
\hline Percentage of participants with SAEs & 4.6 & 5.3 & 5.8 & $\mathrm{~N} / \mathrm{A}^{\mathrm{a}}$ & $\mathrm{N} / \mathrm{A}^{\mathrm{a}}$ & 3.5 & 5.5 \\
\hline SAE rate per 100 PYE & 6.7 & 8.9 & 9.3 & 20.3 & 8.0 & 12.0 & 14.4 \\
\hline \multicolumn{8}{|l|}{ Indian subpopulation } \\
\hline Number of exposed participants & 125 & 65 & 60 & 45 & 18 & 32 & 32 \\
\hline Percentage of participants with AEs & 76.8 & 76.9 & 93.3 & 80.0 & 61.1 & 81.3 & 87.5 \\
\hline $\mathrm{AE}$ rate per $100 \mathrm{PYE}$ & 364.1 & 332.1 & 543.3 & 363.4 & 349.5 & 766.5 & 577.0 \\
\hline Percentage of participants with SAEs & 2.4 & 1.5 & 5.0 & 0.0 & 0.0 & 3.1 & 3.1 \\
\hline SAE rate per 100 PYE & 3.6 & 1.7 & 6.8 & 0.0 & 0.0 & 6.8 & 13.8 \\
\hline
\end{tabular}

See Gough et al. [8], Rodbard et al. [9] and Buse et al. [11] for more detail on these trials

Data are based on safety analysis set

$A E s$ Adverse events, N/A not available, PYE patient-years of exposure, SAEs serious adverse events

${ }^{a}$ Data for percentage of participants with AEs in the entire trial population for DUAL IV have not been published to date

IDegLira was generally weight-neutral when used as an add-on to oral therapy (DUAL I extension/DUAL IV) and resulted in weight loss when used after basal insulin (DUAL II).

Considering IDegLira alone, rates of confirmed hypoglycemia were consistent with those observed with IDegLira in the global trial populations. However, the rate of confirmed hypoglycemia with IDeg was substantially lower in the Indian subpopulations (by around 1.7/ 1.8 events/PYE) versus the global trial populations of DUAL I and II. As a result, the rate of confirmed hypoglycemia was numerically lower with IDeg versus IDegLira in the Indian subpopulations of DUAL I and II, while in the global trial population IDegLira resulted in a lower rate of hypoglycemia versus IDeg, reaching statistical significance in the DUAL I trial $[8,9]$. This difference might be explained by the small number of participants-and therefore hypoglycemic events-in the Indian subpopulations and by baseline differences. The hypoglycemia rates should also be considered in the context of the significantly lower mean end-of-trial $\mathrm{HbA}_{1 \mathrm{c}}$ achieved with IDegLira compared to comparators.

IDegLira was generally well tolerated, with a lower rate of gastrointestinal AEs in the Indian subpopulation versus the global trial populations in DUAL I and IV, and a higher rate in DUAL II. Across all trials, the proportion of participants experiencing AEs was higher in the Indian subpopulation than in the global trial population, but the pattern of AEs did not differ $[8,9,11]$.

An inherent limitation of this study is that it is a post hoc analysis of three randomized controlled DUAL trials that were not designed to compare the safety and efficacy of IDegLira in the Indian subpopulation versus the global population. As such, there were differences at baseline in terms of FPG and BMI with the 
Indian subpopulation compared with the global population. Furthermore, owing to trial design differences, individual trial data were analyzed separately rather than the IDegLira data being pooled, and therefore sample sizes were small. Differences between Indian and non-Indian populations were not analyzed as the Indian population constituted a relatively low proportion of the global population.

\section{CONCLUSION}

In conclusion, results from the Indian subpopulations largely reflected those of the global study populations. These results provide evidence to support the efficacy and safety of IDegLira as a treatment modality for participants with type 2 diabetes uncontrolled on OADs and/or basal insulin of the South Asian population, offering better glucose control than either component alone, improved weight profile versus the basal insulin component, and with fewer gastrointestinal side effects than a GLP-1 analogue.

\section{ACKNOWLEDGEMENTS}

Sponsorship and article processing charges for this study were funded by Novo Nordisk A/S, Bagsvaerd, Denmark. Novo Nordisk A/S were involved in study design, data collection and analysis and reviewed the manuscript for scientific and medical accuracy. All named authors meet the International Committee of Medical Journal Editors (ICJME) criteria for authorship for this manuscript, contributed to the interpretation, critical revision of and approval of the article, take responsibility for the integrity of the work as a whole and have given final approval to the version to be published. Trine Welløv Boesgaard was also involved in research design and Kamilla Begtrup performed data analyses. We confirm that all authors had access to the study data that support this publication. The authors would like to thank the investigators, trial staff and participants for their participation. They thank also David Harvey, Iain Hatch, Victoria Atess and Beverly La Ferla from
Watermeadow Medical, Oxford, UK, for medical writing and editorial assistance, funded by Novo Nordisk.

Disclosures. Kamlesh Khunti has acted as a consultant and speaker for AstraZeneca, Boehringer Ingelheim, Janssen, Novartis, Novo Nordisk, Sanofi-Aventis, Lilly and Merck Sharp \& Dohme. He has received grants in support of investigator and investigator-initiated trials from Novartis, Novo Nordisk, Sanofi-Aventis, Lilly, Janssen, Boehringer Ingelheim and Merck Sharp \& Dohme. He has received funds for research, honoraria for speaking at meetings and has served on advisory boards for AstraZeneca, Boehringer Ingelheim, Janssen, Lilly, Sanofi-Aventis, Merck Sharp \& Dohme and Novo Nordisk. Kamlesh Khunti is supported by the National Institute for Health Research Collaboration for Leadership in Applied Health Research and Care-East Midlands (NIHR CIAHRC-EM), the Leicester CIinical Trials Unit and the NIHR Leicester-Loughborough Diet, Lifestyle and Physical Activity Biomedical Research Unit, which is a partnership between University Hospitals of Leicester NHS Trust, Loughborough University and the University of Leicester, UK. Viswanathan Mohan has acted as consultant and speaker, received research or educational grants from Novo Nordisk, MSD, Novartis, AstraZeneca, Boehringer Ingelheim, USV, Dr. Reddy's Laboratories, Eli Lilly, Lifescan J \& J, Sanofi-Aventis, Roche Diagnostics, Abbott and from several Indian pharmaceutical companies. Sunil M. Jain and Bipin Sethi declare that they have nothing to disclose. Trine Welløv Boesgaard is an employee of, and owns stocks at, Novo Nordisk A/S. Kamilla Begtrup is an employee of, and owns stock at, Novo Nordisk A/S.

Compliance with Ethics Guidelines. This article is based on a post hoc analysis of previously conducted studies and does not involve any new studies of human or animal subjects performed by any of the authors.

Data Availability. The datasets generated during and/or analyzed during the current study are available from the corresponding author on reasonable request. 
Open Access. This article is distributed under the terms of the Creative Commons Attribution-NonCommercial 4.0 International License (http://creativecommons.org/licenses/ by-nc/4.0/), which permits any noncommercial use, distribution, and reproduction in any medium, provided you give appropriate credit to the original author(s) and the source, provide a link to the Creative Commons license, and indicate if changes were made.

\section{REFERENCES}

1. International Diabetes Federation. IDF diabetes atlas, 7th edn. Belgium, Brussels: International Diabetes Federation; 2015. Available at: http:// www.diabetesatlas.org/

2. Mohan V, Shah SN, Joshi SR, et al. Current status of management, control, complications and psychosocial aspects of patients with diabetes in India: results from the DiabCare India 2011 Study. Ind J Endocrin Metab. 2014;18:370-8.

3. American Diabetes Association. Standards of medical care in diabetes-2016. Diabetes Care. 2016;39[Suppl]:S1-112.

4. Gunaranthne A, Patel JV, Potluri R, et al. Increased 5-year mortality in the migrant South Asian stroke patients with diabetes mellitus in the United Kingdom: the West Birmingham stroke project. Int J Clin Pract. 2008;62:197-201.

5. Shah A, Kanaya AM. Diabetes and associated complications in the South Asian population. Curr Cardiol Rep. 2014;16:476.
6. Khunti K, Bellary S, Karamat MA, South Asian Health Foundation, et al. Representation of people of South Asian origin in cardiovascular outcome trials of glucose-lowering therapies in Type 2 diabetes. Diabet Med. 2017;34(1):64-8.

7. Gough SC, Bode B, Woo V, et al. Efficacy and safety of a fixed ratio combination of insulin degludec and liraglutide (IDegLira) compared with its components given alone: results of a phase 3, open-label randomised, 26-week treat-to-target trial in insulin naive patients with type 2 diabetes. Lancet Diabetes Endocrinol. 2014;2:885-93.

8. Gough SC, Bode BW, Woo VC, et al. One-year efficacy and safety of a fixed combination of insulin degludec and liraglutide in patients with type 2 diabetes: results of a 26-week extension to a 26-week main trial. Diabetes Obes Metab. 2015;17(10):965-73.

9. Rodbard HW, Bode B, Harris S, et al. Safety and efficacy of IDegLira added to sulphonylurea alone or sulphonylurea and metformin in insulin-naïve people with Type 2 diabetes: the DUAL IV study. Diabet Med. 2017;34(2):189-96.

10. Doyle ME, Egan JM. Mechanisms of action of glucagon-like peptide 1 in the pancreas. Pharmacol Ther. 2007;113:546-93.

11. Buse JB, Vilsbøll T, Thurman J, et al. Contribution of liraglutide in the fixed-ratio combination of insulin degludec and liraglutide (IDegLira). Diabetes Care. 2014;37:2926-33.

12. Gough S, Buse J, Woo V, et al. One-year efficacy and safety of IDegLira in patients with type 2 diabetes. Diabetes. 2014;63[Suppl 1]:A17 (abstract 65-OR). 